OPEN ACCESS

Approved by:

Frontiers Editorial Office,

Frontiers Media SA, Switzerland

*Correspondence:

Shengtao Yao

YST@zmu.edu.cn

Fang Cao

caof@zmu.edu.cn

tThese authors have contributed equally to this work and share first

authorship

Specialty section:

This article was submitted to

Computational Genomics,

a section of the journal

Frontiers in Bioengineering and

Biotechnology

Received: 27 August 2020 Accepted: 03 September 2020

Published: 23 October 2020

Citation:

Zhang Q, Zhong H, Fan Y, Liu Q, Song J, Yao S and Cao F (2020)

Corrigendum: Immune and Clinical Features of CD96 Expression in

Glioma by in silico Analysis. Front. Bioeng. Biotechnol. 8:599544.

doi: 10.3389/fbioe.2020.599544

\section{Corrigendum: Immune and Clinical Features of CD96 Expression in Glioma by in silico Analysis}

\author{
Qiang Zhang ${ }^{1 \dagger}$, Hua Zhong ${ }^{2 \dagger}$, Yinchun Fan ${ }^{1}$, Qian Liu ${ }^{1}$, Jiancheng Song ${ }^{1}$, Shengtao Yao ${ }^{1 *}$ \\ and Fang $\mathrm{CaO}^{\text {i* }}$ \\ ${ }^{1}$ Department of Cerebrovascular Disease, Affiliated Hospital of Zunyi Medical University, Guizhou, China, ${ }^{2}$ College of Life \\ Sciences, Wuhan University, Wuhan, China
}

Keywords: CD96, glioma, immune checkpoint, prognosis, immunotherapy

\section{A Corrigendum on}

Immune and Clinical Features of CD96 Expression in Glioma by in silico Analysis by Zhang, Q., Zhong, H., Fan, Y., Liu, Q., Song, J., Yao, S., et al. (2020). Front. Bioeng. Biotechnol. 8:592. doi: 10.3389/fbioe.2020.00592

In the published article, there was an error in affiliation 1. Instead of "Department of Cerebrovascular Disease, The First Affiliated Hospital of Zunyi Medical University, Guizhou, China", it should be "Department of Cerebrovascular Disease, Affiliated Hospital of Zunyi Medical University, Guizhou, China”.

The authors apologize for this error and state that this does not change the scientific conclusions of the article in any way. The original article has been updated.

Copyright (๑) 2020 Zhang, Zhong, Fan, Liu, Song, Yao and Cao. This is an open-access article distributed under the terms of the Creative Commons Attribution License (CC BY). The use, distribution or reproduction in other forums is permitted, provided the original author(s) and the copyright owner(s) are credited and that the original publication in this journal is cited, in accordance with accepted academic practice. No use, distribution or reproduction is permitted which does not comply with these terms. 